\title{
Analista-ambiente e analista-objeto como funções na clínica winnicottiana: teoria e ilustrações*1
}

\author{
Analyst-environment and analyst-object \\ as functions of the Winnicottian clinic: \\ theory and illustrations
}

Rosa Maria Tosta*2

Este artigo apresenta uma sugestão de nomenclatura. Proponho nomear duas funções analíticas incluídas no desempenho do psicanalista: função analista-ambiente e função analista-objeto. Muitas vezes o paciente apresenta um nível precário de desenvolvimento e, nesse caso, a função básica de sustentação de self que precisa ser exercida pelo analista, pode ser denominada função ambiental, análoga à função mãe-ambiente inicial. Eu chamo esse papel do psicanalista de analista-ambiente. Da mesma forma, o psicanalista pode alternar suas funções e, para atender a demanda de seu paciente, estar lá como um objeto de necessidade ou de desejo. A esta função psicanalítica chamo analista-objeto. Analista-ambiente e analista-objeto são funções intercambiáveis do psicanalista na clínica. Vinhetas de casos clínicos são apresentadas como ilustrações destes diferentes tipos de função psicanalítica.

Palavras-chave: Analista-ambiente, analista-objeto, funções psicanalíticas, clínica winnicottiana

*1 Artigo revisto e ampliado a partir de trabalho apresentado no XXVI Encuentro sobre el pensamiento de D. W. Winnicott, Ciudad de México, novembro de 2017. Apoio do Plano de Incentivo à Pesquisa - PIPEq-PUC-SP.

*2 Pontifícia Universidade Católica de São Paulo - PUC-SP (São Paulo, SP, Brasil). 


\section{ARTIGOS}

O presente artigo visa apresentar uma indicação de nomenclatura. Proponho nomear duas funções analíticas incluídas na atuação do psicanalista: função analista-ambiente e função analista-objeto.

Quando menciono esta nomenclatura, tomo como ponto de partida a terminologia utilizada por Donald Woods Winnicott com relação aos dois modos de exercício da função materna ou ambiental, a saber, mãe-ambiente e mãe-objeto. $\mathrm{O}$ autor discorre sobre esses dois tipos de relacionamento, especialmente quando apresenta o estágio do desenvolvimento da capacidade para se preocupar.

O presente artigo tem como proposta descrever duas funções do analista - analista-ambiente e analista-objeto - como dois modos de cuidado na clínica psicanalítica winnicottiana, correlacionando-os aos dois modos de cuidado materno, mãe-ambiente e mãe-objeto.

Winnicott (1963/1983c) afirma que não pretende inventar nomes que provoquem confusão, mas considera que os termos mãe-ambiente e mãe-objeto revelam:

[...] dois aspectos do cuidado do lactente, mãe como objeto, ou possuidora do objeto parcial que pode satisfazer as necessidades urgentes do lactente, e a mãe como a pessoa que evita o imprevisto e que ativamente provê o cuidado de sustentar e do manejo global. O que o lactente faz no ápice da tensão do id e o uso que assim faz do objeto me parece muito diferente do uso que faz da mãe com parte do ambiente total. (p. 72)

O autor explicita que a tarefa do estágio de preocupação é a reunião na mente do bebê dos dois modos de cuidado. Segundo Winnicott (1963/1983c), "nesta linguagem é a mãe-ambiente que recebe tudo que pode ser chamado de afeição e coexistência 
sensual; é a mãe-objeto que se torna o alvo da experiência excitante baseada na tensão crua do instinto" (p. 72).

Para que esta complexa tarefa tenha sucesso é preciso a sobrevivência da mãe. Cria-se um círculo benigno, pois há a constituição da capacidade de reparação, capacidade para sentir culpa quando necessário, mas o indivíduo agora pode se preocupar e se sentir responsável pelo outro. ${ }^{1}$

$\mathrm{O}$ autor especifica esses modos de cuidado materno - mãe-ambiente e mãe-objeto —-, correlacionando-os ao modo tranquilo e ao modo excitado de relação que o bebê pode adotar no seu relacionamento com o mundo. Destaque-se que o autor já apresenta estes dois modos de ser do bebê desde o estágio mais primitivo. Isto nos leva a pensar que os dois modos de maternagem podem ser vividos pela mãe antes do estágio de preocupação, quando esses modos são reunidos pelo bebê, pois o modo tranquilo é respondido pela mãe-ambiente e o modo excitado é respondido pela mãe-objeto. Antes do estágio de preocupação, e principalmente nos estágios mais iniciais, o bebê não tem condições de reunir essas funções maternas e esses modos de existência em sua mente.

A questão é que na preocupação o bebê vai reunir as duas mães. Nas palavras do autor: "Minha tese é que a preocupação surge na vida do bebê como uma experiência altamente sofisticada ao se unirem na mente do lactente a mãe-objeto e a mãe-ambiente" (1963/1983c, p. 72). Então, se aqui se reúnem essas duas formas de cuidado, posso supor que anteriormente, na fase de dependência relativa, essas formas de relacionamento com os aspectos do cuidado materno estavam sendo vivenciadas de maneira alternada e não integradas do ponto de vista do eu do bebê. Ora como objeto de busca instintual ora de busca de segurança. O bebê era uma pessoa, mas ainda não uma pessoa completa, com capacidade de se preocupar com o outro. ${ }^{2}$

${ }^{1}$ Embora Winnicott em seus trabalhos utilize o termo "posição depressiva", em seus textos mais maduros, redescreve esse estágio do amadurecimento, nomeando-o de "concern", que foi traduzido para o português como "preocupação", "concernimento" ou mesmo, "envolvimento". Na redescrição winnocottina, a integração dessa etapa relaciona-se à fusão dos impulsos instintuais e dos processos de constituição identitária, do lado do indivíduo, e em relação ao outro, refere-se à integração da mãe-ambiente e mãe-objeto.

${ }^{2}$ A questão da possibilidade de a mãe estar exercendo antes estes modos de cuidado, mas sem a plena consciência por parte da criança, atravessou-me na elaboração deste artigo, mas terá que ser desenvolvida em futuro trabalho. 


\section{ARTIGOS}

Retornando aos modos do ponto de vista do bebê, no modo tranquilo, o bebê pode permanecer em sua quietude de ser e de continuidade de existência. Muito no início esse estado tem a ver com a não integração. Mesmo depois, no modo tranquilo o indivíduo não está voltado para a integração de elementos advindos do exterior. Esse estado de solitude é possibilitado, pois há um ambiente que realiza o holding existencial. No início, quando a mãe está exercendo a função ambiente, essa devoção materna não é percebida pelo bebê. Em outras palavras, a mãe seria como o cenário para que a continuidade de existência do ser do bebê possa acontecer.

Safra (2009) ao retomar a teoria de Winnicott sobre o desenvolvimento emocional mais primitivo, salienta o lugar do silêncio e da solitude na constituição do ser humano. Ele diz que:

[...] um dos aspectos muito importantes na constituição de si mesmo, e também importante na situação clínica, é compreendermos essa dimensão do silêncio e da solitude como experiência de si, para que possamos discriminar entre o registro do objeto e o registro da presença. (p. 77)

O autor completa afirmando que a mãe com sua hospitalidade encarnada oferece ao bebê um encontro fundante. Segundo Safra (2009): “A mãe poderá vir a ser, para o bebê, objeto-presença, objeto sem-presença ou só presença" (p. 78) e "O bebê necessita de encontro com outro humano, que possa ser objeto e presença" (p. 78).

Nas palavras de Winnicott (1963/1983a) "a intercomunicação entre lactente e a mãe ambiente é sutil" e quando a consistência do holding predomina, pode-se dizer que "o lactente se comunica simplesmente por continuar a existir" (p. 166). Pode-se dizer, então, que quando as coisas vão bem, há uma comunicação mutual, ou seja, entre psicossomas sensíveis. Winnicott (1970/1994a) menciona que a comunicação acompanha a experiência pulsional de alimentação. Cita exemplo da brincadeira de um bebê que alimenta a mãe, colocando o dedo em sua boca. Seria uma situação de "alimentação mútua". Então essa primeira comunicação é uma alimentação comunicativa entre corpos vivos. Para o autor a "mutualidade é começo de uma comunicação entre duas pessoas", é a "comunicação entre o bebê e a mãe, algo que é uma questão de experiência e que depende da mutualidade que resulta das identificações cruzadas" (Winnicott, 1970/1994a, p. 198). Salienta ainda que a mutualidade é uma experiência partilhada que é relativa à constituição subjetiva e não se refere ao domínio das pulsões.

No entanto, quando há inconsistência ambiental, o bebê fica perturbado. Quebra-se a mutualidade, e aí o bebê precisa procurar se comunicar, é 
forçado a se adaptar e entra em funcionamento egoico precário e precoce. Daí o ambiente insiste em ser percebido e, assim, passa a ser um objeto ao qual é preciso reagir. Nos casos mais graves, é preciso organizar um falso self adaptativo que proteja o núcleo verdadeiro do self.

$\mathrm{Na}$ normalidade dos primórdios, é possível ocorrer um relacionamento subjetivo com o mundo, onde a criatividade do gesto é protagonista. Objeto subjetivo é o objeto que não é vivido como objeto, pois é uma criação do bebê no período inicial da ilusão de onipotência. Para Winnicott (1970/1994d) "É axiomático que não exista relacionamento com um objeto subjetivo" (p. 221).

De modo análogo, o paciente muitas vezes se apresenta com um nível de desenvolvimento precário, e neste caso a função de sustentação do ser terá que acontecer por parte do analista, a qual pode ser chamada de função ambiente, de forma análoga à função mãe-ambiente dos estágios iniciais. Portanto, o manejo clínico incluiria, de modo necessário e preponderante, a função do psicanalista que denomino de analista-ambiente. Poderíamos dizer que se caracteriza pela presença psicossomática da pessoa do analista e inclui o espaço físico e o setting. Seria a ambiência analítica que tem a ver com toda uma linguagem não verbal e com a sensibilidade e empatia sensível que atravessa a relação analítica. Winnicott (1970/1994a) explicita que há uma regressão para a comunicação mutual nos casos em que necessidade de regressão à dependência se impõe.

Por outro lado, no modo excitado, o indivíduo é acionado por algum impulso instintual que mobiliza uma ação que procura algum objeto no meio ambiente em busca de realização. Na saúde dos primórdios, o gesto procura o objeto que se acha lá para ser encontrado. Quando a criança, em seu estado excitado, busca um objeto de realização ou de satisfação, a mãe exerce o que Winnicott chamou de mãe-objeto. A mãe-objeto é a mãe que é atacada pela excitação instintual, ou seja, a mãe do amor excitado.

Exemplificando, no estágio de uso de objeto, entra em cena com força a destrutividade relativa ao objeto subjetivo, o qual pode se tornar objeto objetivamente percebido - externo — se a mãe sobreviver à destrutividade do bebê.

No início da vida o bebê não tem condições de perceber que a mãe que ele ataca vorazmente é a mesma mãe que o embala e o sustenta. A integração da mãe-ambiente e mãe-objeto só é possível na etapa de preocupação. Winnicott assim descreve as funções maternas: "a mãe é necessária neste período por seu valor de sobrevivência. Ela é uma mãe-ambiente e, ao mesmo tempo, uma mãe-objeto, o objeto de intenso amor" (Winnicott,1963/1983d, p. 96).

Seria a conquista de integrar em si mesmo os dois modos de viver, tranquilo e excitado, e, ao mesmo tempo, unificar a mãe-ambiente e a 


\section{ARTIGOS}

mãe-objeto, diferenciando a mãe como outro. Essa integração, também chamada de fusão, caracteriza a conquista da capacidade para se sentir responsável pelos resultados de seus impulsos, ter capacidade de sentir culpa quando necessário, e preocupar-se com o outro.

Nessa etapa, Winnicott (1963/1983c) diz que “o fracasso da mãe-objeto em sobreviver ou da mãe-ambiente em prover oportunidades consistentes para reparação leva a uma perda da capacidade de se preocupar e à sua substituição por ansiedades e defesas cruas tais como splitting e desintegração" (p. 74). No caso em que o fracasso é generalizado, não se poderia falar de perda e sim de não constituição da capacidade para a integração dos impulsos agressivos na personalidade.

Julgo fundamental realçar que, para que haja o desenvolvimento da capacidade de se preocupar, é necessário que o estágio do uso do objeto tenha sido atingido e, em sequência deste, o estágio do Eu Sou. Assim, no estágio de uso do objeto, o ambiente continua lá, agora com novas atribuições. Sabemos que, na saúde, essa sobrevivência aos ataques favorece a distinção entre fantasia e realidade por parte da criança. Winnicott (1988/1990a) expressa que o bebê destrói a mãe e ela continua viva para receber seu gesto, daí a criança pode dizer que a ama, pois o amor da mãe sobreviveu ao ódio. Quando a mãe não consegue exercer a função ambiental de sobrevivência e não consegue distinguir realidade e fantasia, lança o bebê na incapacidade de manifestação do ódio e impulsos destrutivos e, então, ele passa a atuar na realidade seus impulsos e as ideias correspondentes ficam dissociadas, excluídas da consciência.

Estela Ribeiro Versiani e Luiz Augusto M. Celes (2015) explicitam que há pacientes que chegam à análise sem condições de usar os objetos, continuando no campo de controle onipotente dos objetos de natureza subjetiva. Nesse caso, também o analista não pode ser visto de forma objetiva e colocado fora da área de onipotência. $\mathrm{O}$ analista, neste caso, não tem o status de alteridade. Para que o analista possa ser usado como objeto, há que se passar na análise pela destruição do analista como objeto subjetivo que é possibilitado pela sobrevivência do analista aos ataques do paciente.

É importante lembrar que destruir o analista como objeto subjetivo, colocá-lo como objeto fora de seu domínio, além da sobrevivência e da sustentação do analista, é facilitado pelo fato de o paciente ter conquistado a possibilidade de viver também na área da transicionalidade. Não se trata apenas de colocar de dentro para fora. Um dos paradoxos da teoria winnicottiana refere-se ao fato de que o bebê cria o que está lá para ser encontrado. Lembremos Winnicott (1963/1983a), ao afirmar que o objeto é criado e não encontrado. Mas para ser criado ele precisa ser encontrado. 
Também o analista precisa ser criado pelo paciente o que é possibilitado pelo fato de o analista estar lá para ser encontrado, destruído pelo paciente enquanto objeto subjetivo e criado e recriado inúmeras vezes pela criatividade do paciente.

Safra (2009), ao refletir sobre as várias formas em que o analista retoma as tarefas maternas éticas iniciais, explicita que "o analista pode ser analista-objeto, sem presença. Perspectiva que preocupou Winnicott quando discutia situações nas quais a análise levava o analisando ao estabelecimento de um falso self analítico" (p. 78; grifo meu).

Por outro lado, se o analista for o oposto, só cenário ou mesmo só presença, ele está colocando o paciente em risco. De acordo com Safra (2009): "Complicado é também o analista que é só presença, só silêncio. Nesse caso, ele acaba convidando o analisando a cair num abismo insuportável" (p. 78).

Tal qual no processo de constituição de si mesmo no início da vida, penso que na análise também o analista tem a função analista-ambiente e analista-objeto. Analista-ambiente e analista-objeto são funções intercambiantes do psicanalista na clínica. Poderia se pensar que o analista faz a integração de funções quando interpreta ou quando brinca, pois aí estaria situado num espaço que comporta as contradições. É esperada do analista essa habilidade de exercício flexível de funções que se adequam ao estágio de desenvolvimento emocional de cada paciente, assim como as variações que ocorrem com o mesmo paciente no decorrer do processo analítico ou até numa mesma sessão.

Esta ideia está relacionada à proposta winnicottiana de uma psicanálise de cuidado. Assim, Winnicott (1986/1996), no seu texto "A cura", possibilita pensar a psicanálise como um modo clínico que é, antes de tudo, um "cuidar" ou "cuidar-curar", contrapondo essa proposta terapêutica à teoria do tratamento clínico que visa o curar vigente na medicina.

Uma questão fundamental na prática psicanalítica do cuidado é o trabalho com o manejo da situação clínica. Este há de ser diferenciado conforme a idade emocional do paciente. Assim, em carta de 1953 a Hanna Segal sobre a questão do manejo de psicóticos e neuróticos, Winnicott (1987/1990b) refere que se "uma pessoa madura pode participar de seu próprio manejo, uma criança só pode tomar parte até certo ponto, e um bebê no início depende absolutamente de um ambiente" (pp. 41-42). Conclui dizendo que o manejo varia conforme o nível de desenvolvimento e, como consequência, é essencialmente diferente nos casos dos psicóticos e dos neuróticos. 


\section{ARTIGOS}

Portanto, a atuação do analista estaria relacionada com o manejo da situação clínica. Para Masud Khan (1993) manejo clínico tem a ver com estabelecer condições de espaço psicoterapêutico para o paciente. Mais especificamente, o manejo clínico tem a ver com fornecer a adaptação ambiental na situação clínica que faltou na vida do paciente e que prejudicou o desenvolvimento, tendo levado a um modo reativo de viver.

O manejo pode ser diferenciado de acordo com o modo de apresentação de cada paciente. Quando Winnicott pensou no manejo que possibilitasse a regressão à dependência, estava se referindo aos casos que não tiveram um bom início de vida relacional.

Winnicott (1989/1994b) conceitua regressão para descrever o "estado de um adulto ou de uma criança na transferência (ou qualquer outro relacionamento dependente), quando uma posição avançada é abandonada, restabelecendo-se uma dependência infantil" (p. 37). Nesse processo "o meio ambiente se vê indiretamente incluído, uma vez que a dependência implica um meio ambiente que atenda à dependência" (p. 37).

Então, quando a regressão à dependência se dá na análise, o analista precisa exercer predominantemente a função de cuidado ambiental, outrora fracassada, ou seja, a função analista-ambiente.

Winnicott (1960/1983b), ao trabalhar a questão de contratransferência, explicitando a situação dos pacientes que necessitam de regressão, diz que:

Se se quiser que o self verdadeiro oculto aflore por si próprio, o paciente terá de passar por um colapso como parte do tratamento, e o analista precisará ser capaz de desempenhar o papel de mãe para o lactente do paciente. [...] O analista precisará permanecer orientado para a realidade externa ao mesmo tempo que identificado ou mesmo com o paciente. $\mathrm{O}$ paciente precisa ficar extremamente dependente [...] (p. 149)

Winnicott (1955/1993a; 1986/1996) preconizou um tipo de dispositivo analítico diferenciado, primeiramente ao pensar em casos de psicose, ou seja, quando não houve possibilidade de viver a dependência da "mãe ambiente", aquela que estaria lá para permitir que o bebê só continuasse sua tarefa de continuar a ser. Tais crianças ou adultos necessitam experimentar na situação clínica a dependência que não puderam viver anteriormente, o que leva à demanda de manejo do analista nesse lugar de necessidade do paciente.

Nos casos de tendência antissocial também há uma falha precoce, porém no período de dependência relativa. São indivíduos que viveram falha ambiental significativa ou foram precocemente decepcionados pelo parceiro relacional inicial, quando já tinham uma noção de que a falha provinha do ambiente. 
Em termos sintomatológicos, podem apresentar comportamentos antissociais, através de furtos, mentiras frequentes, roubos ou atos violentos, que procuram incomodar o ambiente, pois precisam de uma reparação da parte do mesmo. Também nesses casos, precisam viver uma regressão à dependência na análise, o que vai exigir do psicoterapeuta uma adaptação fina, mas principalmente uma tolerância, ou uma sustentação de si e do outro, não retaliando o paciente por seus atos destrutivos em relação ao analista, para que o paciente possa perceber a diferença entre sua fantasia e a realidade do outro que continua inalterada e igual a si mesmo, e assim vai revelando que tem uma existência independente do desejo ou da ação do analisando.

Em ambos os casos, Winnicott recomenda um manejo clínico diferenciado em que o mais importante é a função do analista em proporcionar um ambiente confiável, constante, previsível, consistente, continente, funções estas que remetem à função materna inicial. Tais tarefas responderiam às necessidades próprias do modo tranquilo em que o indivíduo pode permanecer apenas sendo, ou seja, na continuidade de ser.

Winnicott (1955/1993a) afirma que "a ênfase está certamente no manejo e às vezes o trabalho analítico comum com esses pacientes deve ficar suspenso por longos períodos, sendo mantido apenas o manejo" (p. 460). Então, estaria predominando o modo analista-ambiente do profissional.

Ao revelar as diferenças fundamentais da teoria de Winnicott em relação à teoria freudiana, Leopoldo Fulgêncio, em texto de 2010, refere a essa questão da necessidade de regressão por parte de determinados pacientes, considerando que tal necessidade não poderia ser atribuída à resistência, relacionada ao processo de repressão, e sim a outro tipo de defesa. Retomando os conceitos winnicottianos sobre o trauma, o autor relembra que tais pacientes passaram por situações traumáticas em termos de fracassos na relação de dependência. Segundo o autor:

Se há resistência, nestes casos, é a resistência em retornar a uma situação de dependência ambiental, uma resistência que não pode ser creditada apenas às capacidades internas do paciente, mas depende, em grande escala, daquilo que o analista-ambiente pode oferecer no contexto do tratamento. (Fulgêncio, 2010, p. 114; grifo meu)

Lembremos quando Winnicott (1974/1994c), em seu texto "Medo do colapso", fala que este medo teria a ver com situações de fracassos ambientais já acontecidas numa época inicial da vida, mas não experienciadas, por que não havia um ego lá para registrá-las, num período em que não havia acesso à linguagem. Então tais experiências são registradas no corpo, congeladas, 


\section{ARTIGOS}

e ficam à espera de um encontro humano significativo, para que possa ser retomada a dependência necessária para que a confiança no outro possa ser reencontrada. Se este for um encontro analítico, estaríamos frente a um processo de regressão à dependência.

Muitos estudiosos da teoria de Donald W. Winnicott destacam a modificação proposta por ele na prática clínica psicanalítica, principalmente pela valorização da experiência de relação humana que se estabelece na clínica, da noção de acontecimento que é trazida nos estudos que revelam o trabalho de Winnicott em sua maturidade, como os dos livros $O$ brincar e a realidade (1971) e de sua proposta de consultas terapêuticas, colocada nos livros Explorações psicanalíticas (1989) e em Consultas terapêuticas em psiquiatria infantil (1971). Esta modificação técnica implica o manejo da situação clínica de forma a favorecer a experiência do aqui e agora, a sustentação do analista do que se passa e, se for o caso, favorecer o processo de regressão à dependência.

Estaria havendo uma modificação do setting psicanalítico. Winnicott (1956/1993b) define setting como "a soma de todos os detalhes do manejo" (p. 486). Considera que quando o ego está intacto, "o analista pode deixar de se preocupar com estes detalhes mais antigos do cuidado materno e, neste caso, o setting da análise não é importante em comparação com o trabalho interpretativo" (p. 483), mas sempre é um fator na análise. No entanto, no trabalho com pacientes que apresentam um falso self, "o setting se torna mais importante que a interpretação" (p. 486). Portanto, aqui estaria falando de um manejo em que a função analista-ambiente é mais relevante.

E o que dizer dos casos que recebemos frequentemente na clínica atual e que não poderiam ser considerados como psicóticos ou manifestando sintomas antissociais como os descritos na literatura? Mas que, por outro lado, também não poderiam ser vistos propriamente como exibindo manifestações que poderiam ser vistas como neuróticas, para os quais a psicanálise foi inicialmente idealizada.

Tenho em mente especialmente dois casos atendidos por aprimorandos na clínica psicológica de uma universidade da cidade de São Paulo, em que as manifestações sintomatológicas são praticamente opostas, que coincidentemente têm o mesmo nome. Trata-se de dois meninos.

Miguel $^{3}$ é um menino que frequentou a clínica por vários anos. Inicialmente em psicoterapia familiar, depois individual, sendo dois anos e

${ }^{3}$ Nomes fictícios 
meio sob minha supervisão. Seu caso chamou minha atenção, pois M. é uma criança que pouco interagiu com os psicoterapeutas durante o seu tratamento, apresentando-se de modo bastante retraído, com significativa dificuldade de contato, o que acarretou a necessidade de manejos diferenciados. Inicio com pequena descrição de seu histórico, para depois relatar pontos mais importantes de seu atendimento.

Em sua casa moram nove pessoas: sua mãe, A., 45 anos; sua avó materna, de 80 anos; seus tios, de 50 anos e de 47 anos; sua tia de 39 anos, referida com problemas mentais, e seus irmãos, o de 21 anos, diagnosticado com esquizofrenia; um com 20 anos e o de 14 anos, em acompanhamento no CAPS infantil e que faz uso de medicação psiquiátrica. O histórico de transtornos de ordem psicótica na família pode fazer supor um ambiente comprometido e sem condições de fornecer o holding necessário para a mãe poder exercer um cuidado adequado. Além disto, com relação à comunicação, a família se mostra disfuncional, pois a avó desautoriza A. na frente das crianças, que podem fazer o que desejam, e os adultos não conseguem exercer autoridade sobre elas. A comunicação é estabelecida através de gritos, castigos, inclusive corporais, como apanhar e bater. Então esse tipo de relacionamento intrafamiliar não 550 provê condições para que Miguel possa se desenvolver quanto às trocas afetivas, tanto com os adultos como com os irmãos.

A questão da ausência de regras na família mostra que a função paterna não se apresenta suficientemente para o garoto. Quanto ao pai, o menino pouco frequenta a casa dele e costuma chorar para não ir. Não fica claro o quanto a pessoa do pai não conseguia ocupar o seu lugar e o quanto essa família matriarcal bloqueou o exercício paterno. Para acrescentar, o casal parental pouco tempo viveu junto e a relação foi tumultuada, permeada por muitas brigas, que aconteciam na frente de seus filhos. Miguel, então, pode ter ficado prejudicado na construção de suas identificações e eleições amorosas.

Miguel dorme na mesma cama que a mãe que justifica o fato de o filho dormir com ela, ao medo do garoto em dormir sozinho, pois se assusta jogando algum jogo violento. Esse fato aponta, no mínimo, para uma dificuldade de separação em relação ao filho. Também sinaliza que a mãe tem o menino como objeto de seu desejo, ou uma continuidade de si mesma, indicando que Miguel não é visto em sua singularidade fundamental, faltando então o holding ético inaugural da condição humana.

Com relação aos atendimentos psicoterapêuticos, inicialmente a procura pelo trabalho de psicoterapia familiar surgiu como uma demanda jurídica, devido a um processo de suposto aliciamento sexual em relação a Miguel (que nunca foi provado) e também levando em consideração as complicações do 


\section{ARTIGOS}

processo de divórcio dos pais. Segundo relatório referente aos atendimentos no processo de terapia de família, o menino se apresentava como uma criança agitada, sem continência, os desenhos apresentavam conteúdos sexuais que fazem referência à experiência do exame de corpo de delito que sofreu. Aqui poderia se levantar a hipótese de que uma situação traumática se sobrepôs à história relacional que per si poderia ser vista como traumática. Assim, o menino viveu quebras significativas em seu processo de amadurecimento, levando a situações nas quais não pode depender, quando precisava depender do ambiente.

Quanto ao processo psicoterápico, a mãe não trouxe uma queixa, pois dizia que Miguel não dava trabalho e que o trazia para tratamento pelo seu temor que ele ficasse com a mesma doença mental do seu filho mais velho. Não demonstrava se preocupar com o menino, e sim consigo mesma. Depois de um tempo, a mãe revelou que o filho passou a demonstrar um comportamento agressivo em casa, com pouca paciência com seus irmãos e quando era forçado a obedecer certas solicitações da mãe, ele tentava resolver a situação agredindo a mãe fisicamente, sendo que esta retribuía a agressão. Nesse aspecto, podemos pensar que A. não exibe um comportamento maduro e, além disto, retalia as agressões da criança. Vimos o quão importante é a sobrevivência do parceiro relacional frente às investidas infantis.

Podemos ler um relato de uma das psicoterapeutas com relação ao início dos atendimentos: "Miguel evitava o contato visual e só me dirigia a palavra quando eu o questionava sobre algo, estava sempre com a cabeça abaixada e se sentava virado para o lado oposto em que eu estava. Ao longo do semestre houve diferenças sutis, pois no final ele senta de frente para mim e permanece com a cabeça erguida, embora não busque contato visual, não se fecha quando eu o faço. Nos primeiros atendimentos abria a caixa lúdica remexia todos os brinquedos, mas sem tirar nenhum deles da caixa; esse movimento costumava durar cerca de 15 minutos até que ele escolhesse um brinquedo para retirar da caixa. O brinquedo era colocado atrás da caixa que posicionava entre ele e eu, como uma barreira". "Trago este relato para enfatizar a extrema inibição do menino que demandou um cuidado da psicoterapeuta, manejando a situação para favorecer a manifestação genuína dele. A psicóloga em sua função analista-ambiente sustentou o tempo necessário para que Miguel pudesse escolher um brinquedo, por exemplo.

${ }^{4}$ Relatório final de atendimento da psicóloga supervisionanda Daliane Grandi (2016). 
A psicóloga que realizou o psicodiagnóstico, também observou que Miguel sempre tentava se esconder entre os cabelos e esconder o que estava fazendo, como se o olhar do outro o ameaçasse. Sentia-se inseguro, o que pode estar relacionado ao pouco contato com grupos secundários e o sentimento persecutório que rondava a família.

$\mathrm{Na}$ maior parte do tempo da psicoterapia, Miguel se manteve calado, ou seja, não apresentou comunicação verbal e quando questionado respondia pontualmente. Lembro-me da paciência e do respeito que definiam a atitude dessa psicoterapeuta, possibilitando os pequenos avanços percebidos no modo de se relacionar do menino.

Talvez o menino tivesse a necessidade de delimitar o seu espaço pessoal ali, em contraponto ao ambiente familiar invasivo. Assim, o menino não desejava que a terapeuta participasse da sua brincadeira, talvez para experimentar estar só na presença do outro. Apontando na mesma direção, necessitando garantir uma privacidade, saliente-se o uso que a criança fazia da caixa lúdica, pois ocorria de tal forma que seu corpo se debruçava sobre a caixa e não permitia que a terapeuta visse o que estava ali dentro e nem quais brinquedos ele manuseava.

Com muita cautela, a terapeuta foi buscando participar, oferecendo-se como objeto para a relação. Assim, por exemplo, quando ele apresentou sua brincadeira de empilhar as vacas, a terapeuta questionou se havia compreendido seu objetivo, ele confirmou que sim que queria empilhar as vacas e depois ela apresentou sugestões de como ele poderia conseguir, o que se realizou.

Desde o início o embotamento afetivo de Miguel se colocou como uma situação angustiante para a psicoterapeuta e exigiu uma sustentação prolongada de silêncios. Também precisava de um olhar interessado por ele, mesmo que inicialmente sem reciprocidade. Sabemos da importância do reconhecimento do outro para a constituição da criança. Nesse manejo de sustentação eu via o modo de a analista-ambiente predominar na atuação da psicoterapeuta, a qual eu, por minha vez, sustentava na supervisão. A evolução no caso de Miguel foi bastante sutil e discreta, mas com o tempo, aceitação do seu modo de ser e com o acolhimento do seu silêncio foi possível passar dos brinquedos escondidos atrás para os jogos de tabuleiro. Da recusa de qualquer contato para a interação de um jogo, onde a resolução dependia da resposta do outro.

Muito difícil foi para a psicoterapeuta sustentar o fechamento do menino, sua escolha pela não comunicação verbal, que não deixa de ser uma forma de comunicar e revelar seu isolamento defensivo. Miguel me pareceu um ser que foi machucado precocemente e isolou seu self encapsulou-se para não ser 


\section{ARTIGOS}

mais invadido. O mais difícil é o analista tolerar a função analista-ambiente de sustentar o self da criança, ficar de pano de fundo.

Citarei uma pequena síntese do outro caso, apenas para mostrar que sintomas opostos de pacientes podem demandar manejos semelhantes do psicoterapeuta.

Miguel, com oito anos, mostrava-se bastante agitado, muito ansioso, impulsivo, e que provocava problemas no ambiente. Anterior ao atendimento individual, em experiência de grupo, notou-se que as outras crianças tentavam excluí-lo das brincadeiras, assim como é excluído nas excursões, pois a professora alega que não conseguiria "controlá-lo" (sic). Tem uma relação exclusiva com a mãe, com pai ausente. Fato é que dificilmente se conseguia estabelecer algum diálogo na situação analítica. $\mathrm{Na}$ análise quase sempre havia uma brincadeira com futebol ou basquetebol, pois o menino sonhava em ser goleiro. Esse modo de brincadeira poderia ser lido como um jogo repetitivo, no entanto, entendo que ele também estaria apresentando seu sonho de futuro nesse brincar. Percebo que tanta ansiedade e agitação camuflam uma dificuldade grande de se comunicar com o outro e, ainda, do outro acessar sua intimidade, embora houvesse essa busca incessante de contato por parte do menino. Então, o analista precisa estabelecer um tipo de comunicação mais direta, característica de modos mais iniciais de comunicação na vida e, portanto, envolvendo mais a corporeidade e a linguagem não verbal.

Nesse manejo diferenciado, o psicoterapeuta exerce a função analista-ambiente na maior parte do tempo ao estar sustentando o modo peculiar de ser de seu paciente. E, ao mesmo tempo, pode exercer função analista-objeto ao corresponder às demandas de parceria nos jogos.

Assim, da parte da analista também foi é necessário trabalhar na supervisão sua frustração, pois não havia o que "interpretar"; é o próprio analista que se oferece na função de sustentação desse jogo de apresentação de self e de comunicação mutual. Sabemos que a tarefa do analista exige um exercício de paciência e respeito ao jeito de ser e de se comunicar do outro, mas neste tipo de caso, essa tarefa analítica de sustentação é praticamente o que há para ser feito.

Safra (2009) lembra que em alguns casos na clínica atual há a busca do silêncio-presença do analista. Há indivíduos que procuram na análise um "encontro humano em que o rosto possa ser silêncio. Silêncio que seja hospitalidade, e não indiferença" (p. 79). Complementa dizendo que "São pessoas que precisam desconstruir o objeto para encontrar a presença, precisam desconstruir o excesso de funcionalidade na busca do silêncio, que possa devolvê-los aos fundamentos de si” (p. 79). 
Notemos que nos dois casos relatados, todo tempo, a nosso ver, há uma dificuldade de comunicação nos termos habituais por parte da criança e uma dificuldade do psicoterapeuta de acessar o paciente, pois o que revela é outro tipo de comunicação — mais direta, mutual ou psicossomática - que demandaria o predomínio da função analista-ambiente.

Esse tipo de comunicação exige da parte do psicoterapeuta a aceitação da necessidade de regressão à dependência do paciente, e a psicoterapia faz-se através do manejo clínico diferenciado para que possa criar um espaço possível de manifestação ou apresentação do self da criança. Fica claro que não se trata, então, de trabalhar com a representação que poderia demandar interpretação e, sim, de fornecer condições para que o paciente possa realizar a apresentação de si, e que haja acontecimentos na situação analítica, experiências, o que demanda sustentação ou holding relacional.

Seria mais uma psicoterapia ou clínica de cuidado do que uma cínica da interpretação, pois tais pacientes expressam a necessidade advinda de seu self relativa à demanda de outro devotado, e não da ordem do desejo.

Então, o que unificaria a demanda por um atendimento com manejo diferenciado, com predomínio da função mãe-ambiente do psicanalista seria a necessidade de regressão à dependência no espaço analítico. Nos casos considerados neuróticos, embora o manejo se faça presente e o setting seja fundamental, é a função analista-objeto que se torna preponderante, pois aí o indivíduo já conquistou o status de pessoa inteira e consegue lidar com outra pessoa.

Assim, o analista no seu mister de poder ser o parceiro qualificado dessa relação de intimidade profunda de um manejo clínico diferenciado, há que estar com sua presença psicossomática, em contato com a humildade de se colocar disponível para o outro, com sua presença e ambiência e como objeto do gesto de seu paciente. Como recompensa, o analista pode sair extremamente enriquecido dessa viagem por poder viver esta experiência de encontro humano singular.

Para finalizar, é necessário fazer algumas anotações. Primeiramente, formulei esta proposta de nomenclatura baseada em minha própria experiência clínica e também na experiência de supervisão de inúmeros psicólogos em formação. Só depois, ao escrever este artigo, busquei se outros autores também pensaram nessa questão das funções do psicanalista na prática clínica e explicito tais autores neste texto.

Em um trabalho deste tipo, muito não foi dito. Fizemos um recorte muito específico para colocar os dois termos propostos, isto é, analista-ambiente e analista-objeto. O principal a ser adicionado seria todo o universo simbólico 


\section{ARTIGOS}

na análise. Tal mundo se abre com a integração dos aspectos de viver na pessoa, que podem ser vistos de diferentes ângulos: ambiente e objeto; subjetivo e objetivo; calmo e animado; interno e externo. O mundo dos sonhos e a poesia da existência é o que se abre na área infinita da tangência da experiência, no espaço potencial da rolagem das cortinas de transicionalidade que interferem com o interior e o exterior e não é encontrado em nenhum lugar, pela natureza fluida do mundo da ilusão.

\section{Referências}

Fulgêncio, L. (2010). Aspectos gerais da redescrição winnicottiana dos conceitos fundamentais da psicanálise freudiana. Psicologia USP, 21(1), 99-125.<https:// dx.doi.org/10.1590/S0103-65642010000100006>.

Khan, M. R. (1993). Prefácio. In D.W.Winnicott, Textos selecionados: da pediatria à psicanálise (pp. 7-61). Rio de Janeiro, RJ: Francisco Alves.

Safra, G. (2009). Dimensões do silêncio: a constituição do si mesmo e perspectivas clínicas. Cadernos de Psicanálise - CPRJ, 31(22), 75-82. Recuperado em 24 nov. 2018 de: $<$ http://cprj.com.br/imagenscadernos/06.Conferencia_de_Gilberto_Safra. pdf $>$.

Versiani, E. R., \& Celes, L. A. M. (2015). Reconhecendo a alteridade do analista uma caracterização do trabalho analítico fundamentado no cuidado. Psicologia Clínica, 27(1), 213-223. <https://dx.doi.org/10.1590/0103-56652015000100012>.

Winnicott, D. W. (1983a). Comunicação e falta de comunicação levando ao estudo de certos opostos. In D. Winnicott, O ambiente e os processos de maturação (pp. 163-174). Porto Alegre, RS: Artes Médicas. (Trabalho original publicado em 1963).

Winnicott, D. W. (1983b). Contratransferência. In D. W. Winnicott, O ambiente e os processos de maturação: estudos sobre a teoria do desenvolvimento emocional (pp. 145-151). Porto Alegre, RS: Artes Médicas. (Trabalho original publicado em 1960).

Winnicott, D. W. (1983c). O desenvolvimento da capacidade de se preocupar. In D. W. Winnicott, $O$ ambiente e os processos de maturação: estudos sobre a teoria do desenvolvimento emocional (pp. 70-78). Porto Alegre, RS: Artes Médicas. (Trabalho original publicado em 1963).

Winnicott, D. W. (1983d). Moral e Educação. In D. W. Winnicott, O ambiente e os processos de maturação: estudos sobre a teoria do desenvolvimento emocional (pp. 88-98). Porto Alegre, RS: Artes Médicas. (Trabalho original publicado em 1963). 
Winnicott, D. W. (1990a). Natureza humana. Rio de Janeiro, RJ: Imago. (Trabalho original publicado em 1988).

Winnicott, D. W. (1990b). O gesto espontâneo. São Paulo, SP: Martins Fontes. (Trabalho original publicado em 1987).

Winnicott, D. W. (1993a). Aspectos clínicos e metapsicológicos da regressão dentro do setting psicanalítico. In D.W.Winnicott, Textos selecionados: da pediatria à psicanálise (pp. 459-481). Rio de Janeiro, RJ: Francisco Alves. (Trabalho original publicado em 1955).

Winnicott, D. W. (1993b). Variedades clínicas da transferência. In D. W. Winnicott, Textos selecionados: da pediatria à psicanálise (pp. 483-489). Rio de Janeiro, RJ: Francisco Alves. (Trabalho original publicado em 1956).

Winnicott, D. W. (1994a). A experiência mãe-bebê de mutualidade. In C. Winnicott, R. Shepherd, \& M. Davis (Orgs.), Explorações psicanaliticas: D. W. Winnicott (pp. 195-202). Porto Alegre, RS: Artes Médicas Sul. (Trabalho original publicado em 1970).

Winnicott, D. W. (1994b). Ideias e definições. In C. Winnicott, R. Shepherd, \& M. Davis (Orgs.), Explorações psicanaliticas: D.W.Winnicott (pp. 36-37). Porto Alegre, RS: Artes Médicas Sul. (Trabalho original publicado 1989).

Winnicott, D. W. (1994c). O medo do colapso. In C. Winnicott, R. Shepherd, \& M. Davis (Orgs.), Explorações psicanalíticas: D. W. Winnicott (pp. 70-76). Porto Alegre, RS: Artes Médicas Sul. (Trabalho original publicado em 1974).

Winnicott, D. W. (1994d). Individuação. In C. Winnicott, R. Shepherd, \& M. Davis (Orgs.), Explorações psicanalíticas: D. W. Winnicott (pp. 219-222). Porto Alegre, RS: Artes Médicas Sul. (Trabalho original publicado em 1970).

Winnicott, D. W. (1996). A cura. In D.W. Winnicott, Tudo começa em casa (pp. 87-93). São Paulo, SP: Martins Fontes. (Trabalho original publicado em 1986).

\section{Resumos}

(Analyst-environment and analyst-object as functions of the Winnicottian clinic: theory and illustrations)

This paper presents a suggested nomenclature. I propose to name two analytical functions that are part of the psychoanalyst's performance: the analyst-environment function and the analyst-object function. Patients often present a precarious level of development and in such cases, the basic function of sustaining the self that needs to be performed by the analyst may be called an environmental function, analogous to the initial mother-environment function. I call this role played by the psychoanalyst analyst-environment. Likewise, a psychoanalyst may alternate his functions and, to 


\section{ARTIGOS}

meet the need of a patient, perform the role of an object of a certain need or desire. This psychoanalytic function may be called analyst-object. Analyst-environment and analyst-object are interchangeable functions played by the psychoanalyst in his clinic. Clinical case vignettes are presented to illustrate these different types of psychoanalytic functions.

Key words: Analyst-environment, analyst-object, psychoanalytic functions, Winnicottian clinic

(Analyste-environnementet et Analyste-objet en tant que fonctions dans la clinique winnicottienne: théorie et illustrations)

Cet article présente une suggestion de nomenclature. Je propose de nommer deux fonctions analytiques qui relèvent de la performance du psychanalyste : la fonction analyste-environnement et la fonction analyste-objet. Les patients présentent souvent un niveau de développement précaire et dans ce cas, la fonction basique d'auto-maintient que l'analyste doit alors exercer peut être qualifiée de fonction environnementale, analogue à la fonction mère-environnement initiale. J'appelle ce rôle que le psychanalyste assume analyste-environnement. De façon analogue, le psychanalyste peut alterner ses fonctions et, pour répondre à la demande de ses patients, figurer comme l'objet d'un besoin ou d'un désir. J'appelle cette fonction psychanalytique analyste-objet. Analyste-environnement et analyste-objet sont des fonctions interchangeables du psychanalyste en clinique. Des vignettes de cas cliniques sont présentées à titre d'illustrations de ces différents types de fonctions psychanalytiques.

Mots clés: Analyste-environnement, analyste-objet, fonctions psychanalytiques, clinique winnicottienne

(Analista-ambiente y analista-objeto como funciones en la clínica winnicottiana: teoría e ilustraciones)

Este artículo presenta una sugerencia de nomenclatura. Propongo nombrar dos funciones analíticas incluidas en el desempeño del psicoanalista: función analistaambiente y función analista-objeto. Muchas veces, el paciente presenta un bajo nivel de desarrollo y, en este caso, la función básica de soporte de self, que debe ejercer el analista, puede ser denominada función ambiental, análoga a la función madreambiente inicial. Identifico este papel del psicoanalista como analista-ambiente. De la misma forma, el psicoanalista puede alternar sus funciones y, para atender la demanda de su paciente, estar allí como un objeto de necesidad o de deseo. A esta función psicoanalítica la denomino analista-objeto. Analista-ambiente y analistaobjeto son funciones intercambiables del psicoanalista en la clínica. Se presentan viñetas de casos clínicos para ilustrar estos diferentes tipos de función psicoanalítica.

Palabras clave: Analista-ambiente, analista-objeto, funciones psicoanalíticas, clínica winnicottiana 
(Analytiker-Umgebung und Analytiker-Objekt als Funktionen in Winnicotts Klinik: Theorie und Illustrationen)

Dieser Artikel enthält einen Vorschlag einer Nomenklatur. Es werden zwei analytische Funktionen beschrieben, die zur Rolle des Psychoanalytikers gehören: die Funktion des Analytikers als Umgebung und die des Analytikers als Objekt. Häufig befinden sich die Patienten in einem prekären Entwicklungsstand und in solchen Fällen kann die grundlegende Unterstützungsfunktion, die der Analytiker ausüben muss, als Umgebungsfunktion bezeichnet werden, analog zur ursprünglichen MutterUmgebungsfunktion. Ich bezeichne diese Rolle des Psychoanalytikers als AnalytikerUmgebung. In gleicher Weise kann der Psychoanalytiker seine Funktionen anpassen und, um den Bedürfnissen seiner Patienten entgegenzukommen, als Objekt einer Notwendigkeit oder eines Wunsches fungieren. Diese psychoanalytische Funktion wird Analytiker-Objekt genannt. Analytiker-Umgebung und Analytiker-Objekt sind austauschbare Funktionen des Psychoanalytikers während der Klinik. Klinische Fallvignetten werden zur Illustration dieser psychoanalytischen Funktionen benutzt.

Schlüsselwörter: Analytiker-Umgebung, Analytiker-Objekt, psychoanalytische Funktionen, Winnicotts Klinik

Citação/Citation: Tosta, R. M. (2019, setembro). Analista-ambiente e analista-objeto como funções na clínica winnicottiana: teoria e ilustrações. Revista Latinoamericana de Psicopatologia Fundamental, 22(3), 540-559. http://dx.doi.org/10.1590/1415-4714.2019v22n3p540-8

Editora/Editor: Profa. Dra. Ana Maria G. R. Oda

Submetido/Submitted: 5.2.2019 / 2.5.2019 Versão Revisada/Revised Date: 11.6.2019 / 6.11.2019

Aceito/Acepted: $5.8 .2019 / 8.5 .2019$ 


\section{ARTIGOS}

Copyright: (C) 2009 Associação Universitária de Pesquisa em Psicopatologia Fundamental/ University Association for Research in Fundamental Psychopathology. Este é um artigo de livre acesso, que permite uso irrestrito, distribuição e reprodução em qualquer meio, desde que o autor e a fonte sejam citados / This is an open-access article, which permits unrestricted use, distribution, and reproduction in any medium, provided the original authors and sources are credited.

Financiamento/Funding: Este trabalho teve apoio do Plano de Incentivo à Pesquisa - PIPEq da Pontifícia Universidade Católica de SãoPaulo - PUC-SP (São Paulo, SP, Br) / This work was supported by the Plano de Incentivo à Pesquisa - PIPEq da Pontifícia Universidade Católica de SãoPaulo - PUC-SP (São Paulo, SP, Br)

Conflito de interesses/Conflict of interest: A autora declara que não há conflito de interesses / The author declares that there is no conflict of interest.

\section{Rosa Maria Tosta}

Psicóloga, psicoterapeuta, supervisora e orientadora. Doutora em Psicologia Clínica e Professora do Programa de Estudos pós-graduados em Psicologia Clínica da Pontifícia Universidade Católica de São Paulo - PUC-SP (São Paulo, SP, Br), no Núcleo de Método Psicanalítico e Formações da Cultura. Membro do Espaço Potencial Winnicott - EPW do Departamento de Psicanálise do Instituto Sedes Sapientiae (São Paulo, SP, Br).

Rua Monte Alegre, 984/t-52 - Perdizes

05014-901 São Paulo, SP, Br.

rosamariarmt@terra.com.br • romtost@pucsp.br

https://orcid.org/0000-0003-1166-3398

This is an open-access article, which permits unrestricted use, distribution, and reproduction in any medium for non-commercial purposes provided the original authors and sources are credited. 